\title{
Evaluating the Performance of Cumulus Convection Parameterization Schemes in Regional Climate Modeling System
}

\author{
Sridhara Nayak* and Suman Maity \\ Centre for Oceans, Rivers, Atmosphere and Land Sciences \\ Indian Institute of Technology Kharagpur, West Bengal, India-721302
}

\begin{abstract}
In this study, we explored the performance of the cumulus convection parameterization schemes of Regional Climate Modeling System (RegCM) towards the Indian summer monsoon (ISM) of a catastrophic year through various numerical experiments conducted with different convection schemes (Kuo, Grell amd MIT) in RegCM. The model is integrated at 60KM horizontal resolution over Indian region and forced with NCEP/NCAR reanalysis. The simulated temperature at $2 \mathrm{~m}$ and the wind at $10 \mathrm{~m}$ are validated against the forced data and the total precipitation is compared with the Global Precipitation Climatology Centre (GPCC) observations. We find that the simulation with MIT convection scheme is close to the GPCC data and NCEP/NCAR reanalysis. Our results with three convection schemes suggest that the RegCM with MIT convection scheme successfully simulated some characteristics of ISM of a catastrophic year and may be further examined with more number of convection schemes to customize which convection scheme is much better.
\end{abstract}

Key words: RegCM, Indian Summer Monsoon, Cumulus Convection Schemes

*Corresponding author's present address:

Disaster Prevention Research Institute, Kyoto University, Japan

Email: nayak.sridhara.2n@kyoto-u.ac.jp

\section{Introduction}

The usage of Regional Climate Modeling System (RegCM) towards climate simulation has been steadily increasing over the years. It is widely used over India [1-5], Phippine [6], Iran [7], United States [8], Eastern Africa [9], Korean Peninsula region [10], Japan [11], Northern China [12], East Asia [13-14]. Previous studies show that RegCM successfully simulated the Indian summer monsoon (ISM). However, most of those studies are conducted either for a few years or climatological period with a single cumulus convection scheme of RegCM or through a sensitivity of different cumulus convection schemes of RegCM [15-17]. The 1998 ISM season brought several incidents of socioeconomic loss. During this season, more than 2,800 casualties in India are reported due to extreme rainfalls and floods. Moreover, the extreme temperatures above $50^{\circ} \mathrm{C}$ were felt over some Indian regions during mid-May of 1998 (during premonsoon) that resulted in at least 2,500 causalities. During JuneAugust of 1998 the upper-level monsoon ridge was reported stronger than average over the Indian subcontinent [18]. This study also suggested this ridge has a linkage to the features of a large scale circulation that caused extreme precipitations over Indian regions. However, studies are limited that conducted with sensitivity of various cumulus convection schemes in RegCM towards the ISM of catastrophic years. Thus, in this study an attempt is made to perform simulations with various convections schemes of RegCM to examine their 
performance towards the ISM of a catastrophic year.

\section{Data and Methods}

We used the RegCM version 3 [19-21] and used the radiation scheme of the National Centre for Atmospheric Research based CLM and the PBL scheme given by Holtslag et al. [22]. The feedback from land surface process and their interaction was given from the Biosphere Atmosphere Transfer Scheme and the convective precipitation was computed through one of the three cumulus convection parameterization schemes, viz., Modified-Kuo, Grell with two assumptions (Frisch-Chappell convective closure and Arakawa-Schubert convective closure), and MIT-Emanuel.

The model domain was set up taking India as a center covering the region 6298E and 7-35oN (Figure 1) at $60 \mathrm{~km}$. We

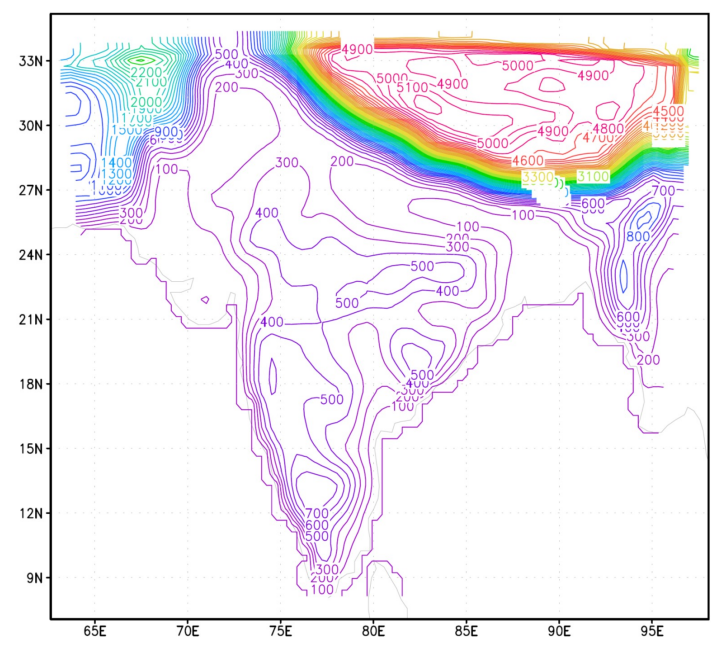

Fig.1: Model domain and Topography (in meter) at $60 \mathrm{~km}$ resolution

used 23 vertical levels and simulated for four continuous months starting from June through September (JJAS) for the year 1998. The NCEP/NCAR reanalysis (NNRP1) data was used to provide the initial and boundary conditions. The United States Geographical Survey (USGS) land use data was used to provide the terrain heights and land use. The simulations were performed through extensive sensitivity studies on three cumulus convection parameterization schemes (Grell, Kuo and MIT). Four numerical experiments were performed with each cumulus convection parameterization schemes viz. Grell with Arakawa-Schubert, Grell with FritschChapel, Kuo, and MIT to test the suitability of schemes towards simulation of the 1998 ISM.

\section{Results and Discussions}

\subsection{JJAS Mean Surface Air Temperature}

The model simulated and NCEP/NCAR Reanalysis seasonal mean surface air temperature during ISM of 1998 i.e. JJAS are shown in figure 2a-e. It showed the JJAS mean surface air temperature that simulated by the Grell with Fritsch-Chapel (Figure 2a), Grell with Arakawa-Schubert (Figure 2b), Kuo (Figure 2c), MIT (Figure 2d) convection schemes and that of from NCEP (Figure 2e). It showed that the simulated JJAS mean temperature over Himalayan region agreed well with NCEP. It also showed that Grell scheme with both the closure assumptions (Fritsch-Chapel and Arakawa-Schubert) underestimated the JJAS mean temperature by $2^{\circ} \mathrm{C}$ over IndoGangetic region, $3 \circ \mathrm{C}$ over Peninsular India and 1 으 $\mathrm{C}$ over Bay of Bengal (Figure 2a, b, e), whereas the simulations from Kuo and MIT scheme agreed well with NCEP over IndoGangetic, Bay of Bengal and under predicted by $2{ }^{\circ} \mathrm{C}$ over Peninsular India (Figure 2c, d, e). It was also observed from figure 2 that except the Kuo scheme, the model predicted the high temperatures over northwest India satisfactorily and agreed well with the forced data, whereas the Kuo scheme under predicted it by $3 \circ \mathrm{C}$. The overall analysis from each convection scheme of the model indicated the MIT scheme performed well towards the JJAS mean temperature of 1998. 

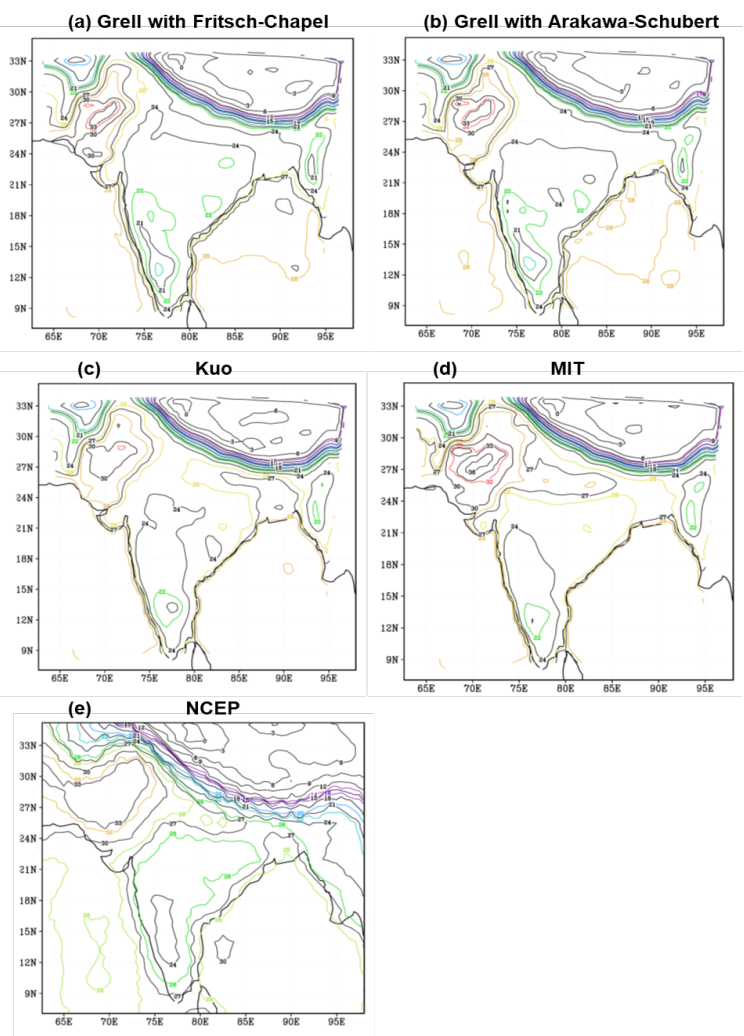

Fig. 2: JJAS mean surface air temperature (in C) for (a) Grell with Fritsch-Chapel, (b) Grell with Arakawa-Schubert, (c) Kuo, (d) MIT convection schemes and (e) NCEP

\subsection{JJAS Mean Precipitation Rate}

Figure 3 presents the precipitation distribution of JJAS mean precipitation rate simulated by Grell (Figure 3a, b), Kuo (Figure 3c), MIT (Figure 3d) scheme and computed from NCEP reanalysis (Figure 3e). The model derived JJAS mean precipitation rate was studied in this section and was validated against NCEP. It showed that except for the MIT scheme, the model under predicted the JJAS mean precipitation rate by $5 \mathrm{~mm} /$ day over Himalayan region, whereas the MIT scheme predicted higher by $2 \mathrm{~mm} /$ day. The Grell with Arakawa-Schubert and Kuo scheme under predicted the JJAS mean precipitation by $5 \mathrm{~mm} /$ day over IndoGangetic region, whereas the simulation from Grell with Fritsch-Chapel scheme agreed with NCEP and MIT scheme predicted higher by $2 \mathrm{~mm} /$ day. Similarly, the
Grell with Arakawa- Schubert and Kuo scheme under predicted the JJAS mean precipitation by $5 \mathrm{~mm} /$ day over Peninsular India and Bay of Bengal, whereas the Grell with Fritsch-Chapel and MIT scheme predicted higher by $2 \mathrm{~mm} /$ day over Peninsular India and $7 \mathrm{~mm} /$ day over Bay of Bengal. The overall analysis and precipitation distribution from each scheme of the model indicated that performance of the Grell with Fritsch-Chapel scheme seemed less suitable than MIT scheme.
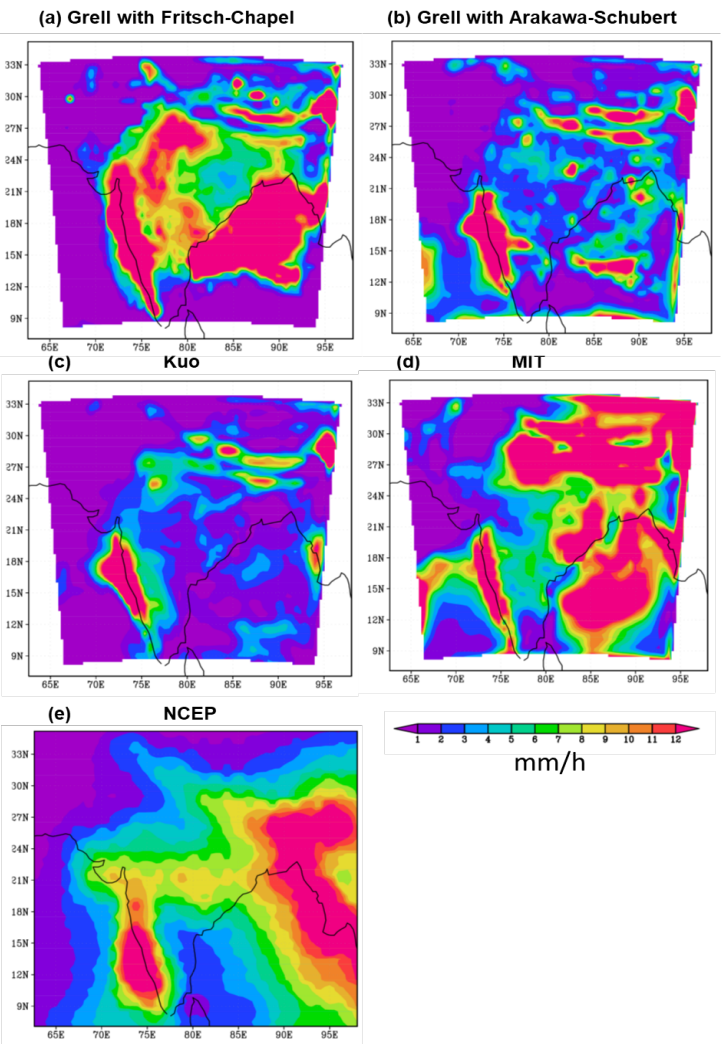

Fig. 3: Same as figure 2, but with JJAS mean precipitation rate

\subsection{Daily Surface Temperature over India}

Figure 4 presents the surface temperature averaged over India during June-September of 1998 for Grell, Kuo, MIT scheme and NCEP. It showed that Grell scheme with Fritsch-Chapel and Arakawa-Schubert underestimated the daily temperature by $\sim 3.3 \circ \mathrm{C}$ during June and $\sim 2 \circ \mathrm{O}$ during JulySept, whereas Kuo and MIT scheme 
underestimates by $\sim 2.6 \circ \mathrm{C}$ and $\sim 2.3 \circ \mathrm{C}$ respectively during June and by $\sim 1$ 으 $\mathrm{C}$ and $\sim 0.7 \circ \mathrm{C}$ respectively during July-Sept. This indicated that the MIT scheme performed better than Grell and Kuo.

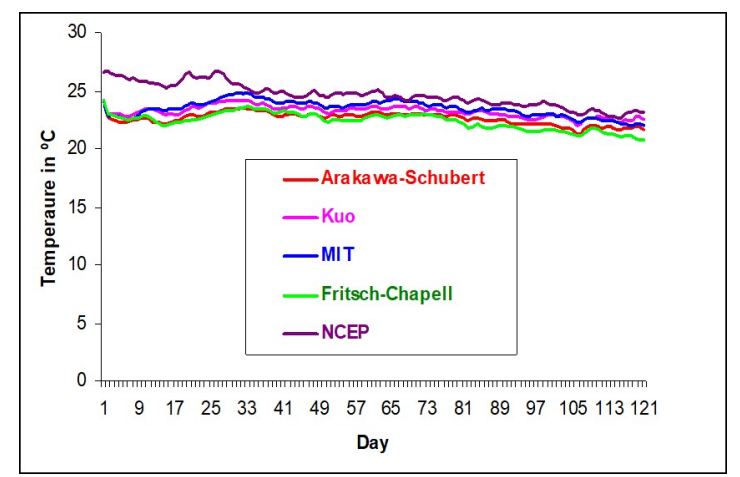

Fig. 4: Daily surface air temperature (in C) over India from June to September

\subsection{Accumulated Rainfall}

The simulated accumulated rainfall over India from the model, NCEP reanalysis, and the Global Precipitation Climatology Centre (GPCC) are given in figure 5 . It showed that the Kuo scheme simulated $28 \mathrm{~mm}$ of rainfall during June, $72 \mathrm{~mm}$ during July, $56 \mathrm{~mm}$ during August, and $28 \mathrm{~mm}$ during September. Similarly, the Grell scheme with Arakawa-Schubert simulated $55 \mathrm{~mm}$, $107 \mathrm{~mm}, 90 \mathrm{~mm}$, and $54 \mathrm{~mm}$ of rainfall during June, July, August, and September respectively. The Grell Scheme with FritschChapel simulated $79 \mathrm{~mm}, 189 \mathrm{~mm}, 167 \mathrm{~mm}$, and $101 \mathrm{~mm}$ of rainfall during each month of JJAS respectively. The NCEP reanalysis produces $198 \mathrm{~mm}, 241 \mathrm{~mm}, 205 \mathrm{~mm}$, and $174 \mathrm{~mm}$ of rainfall during each month of JJAS respectively. Similarly, the MIT scheme simulated $135 \mathrm{~mm}, 253 \mathrm{~mm}, 231 \mathrm{~mm}$, and $149 \mathrm{~mm}$ of rainfall during June, July, August, and September respectively. It was also observed from the figure 5 that GPCC showed $148 \mathrm{~mm}, 255 \mathrm{~mm}, 246 \mathrm{~mm}$, and $159 \mathrm{~mm}$ of rainfall during June, July, August, and September respectively. This indicated that the simulations from MIT scheme were more close to both the NCEP and GPCC than the other schemes of the model during JJAS.

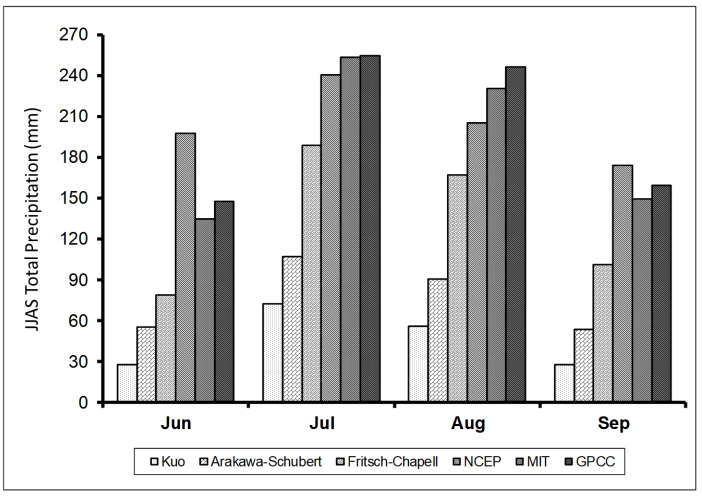

Fig. 5: Accumulated rainfall (in $\mathrm{mm}$ ) over India for June, July, August, and September as simulated by the model, NCEP and GPCC

The overall analysis indicated that the RegCM model with MIT scheme outperformed the JJAS temperature and precipitation compared to other two schemes. We believe our study will be useful for the researchers working on atmospheric dynamics, especially for extreme weather events. For instance, many recent studies revealed that extreme rainfall events over India may increase in future warming atmosphere according to the Clausius-Clapeyron relationship [23]. Furthermore, the land use changes also greatly influence the temperature [24-27], thus more accurate land use representation of the year of simulation may improve the simulated results. However, our preliminary results are based on the three convection schemes in RegCM. So we would like to prepare land use data [28-29] of the catastrophic year and further use more number of convection schemes [17] to examine which scheme performs better for catastrophic years.

\section{Conclusions}

The Regional Climate Modeling System was used to evaluate the performance towards the ISM of a catastrophic year through the sensitivity studies on the various convection schemes. The results indicated that the MIT scheme of the model successfully simulated 
the JJAS mean surface air temperature. The result also indicated that the MIT scheme underestimated the accumulated rainfall during June-Sept when compared to GPCC and overestimated when compared to NCEP during JJAS. Our overall study indicated that the model could successfully simulate some characteristics of ISM of a catastrophic year.

Acknowledgements The authors gratefully acknowledge ICTP, Triesty, Italy for providing the RegCM. Authors also gratefully acknowledge GPCC and NCEP/NCAR for providing observed and reanalysis temperature datasets respectively. Indian Institute of Technology Kharagpur is acknowledged for providing the required facilities for conducting the research work.

\section{References}

1. Bhaskaran, B. R., Jones, G. J., Murphy, M. and Noguer, M. (1996) Simulations of the Indian summer monsoon using a nested regional climate model: domain size experiments. Climate Dynamics, v. 12, pp. 573-587.

2. Dimri, A. P. and Ganju, A. (2007) Wintertime Seasonal Scale Simulation over Western Himalaya Using RegCM3. Pure and applied Geophysics, v. 164, pp. 1733-1746.

3. Maity, S., Satyanarayana, A. N. V., Mandal, M. and Nayak, S. (2017a) Performance evaluation of land surface models and cumulus convection schemes in the simulation of Indian summer monsoon using a regional climate model. Atmospheric Research, v. 197, pp. 21-41.

4. Nayak S, Mandal M, Maity S (2018) RegCM4 simulation with AVHRR land use data towards temperature and precipitation climatology over Indian region. Atmospheric Research, $v$. 214, pp. 163-173.

5. Nayak, S., Mandal, M. and Maity, S. (2019) Performance evaluation of RegCM4 in simulating temperature and precipitation climatology over India. Theoretical and Applied Climatology, v. 137(1-2), pp. 105910751.

6. Francisco, R.V., Argete, J., Giorgi, F., Pal., J., Bi, X. and Gutowski W. J. (2006) Regional model simulation of summer rainfall over the Philippines: Effect of choice of driving fields and ocean flux schemes. Theoretical and Applied Climatology, v. 86, pp. 215227.

7. Babaeian, I., Modirian, R. and Karimian, M. (2007) Sensitivity Analysis of Different Convection Schemes and Domain Centers for Numerical Simulation of Winter Precipitation over Iran. Journal of Aerospace Science and Technology, v. 4(2), pp. 33-42.

8. Walker, M. D. and Diffenbaugh, N. S. (2009) Evaluation of high-resolution simulations of daily-scale temperature and precipitation over the United States. Climate dynamics, v. 33(7-8), pp. 1131.

9. Davis, N., Bowden, J., Semazzi,F. Xie, L. and Onol, B. (2009) Customization of RegCM3 Regional Climate Model for Eastern Africa and a Tropical Indian Ocean Domain. Journal of Climate, v. 22, pp. 3595-3616.

10. Eun, S., Moon, H., Won, T. and Steven., C. (2007) Projected Change in Mean and Extreme Climate over Korea from a Double-Nested Regional Climate Model Simulation. Journal of the Meteorological Society of Japan, v. 85(6), pp. 717732.

11. Oshima, N., Kato, H. and Kadokura, S. (2002) An application of statistical 
downscaling to estimate surface air temperature in Japan. Journal of Geophysical Research-Atmospheres, v. 107 (D10), pp. 4095.

12. Sen, O. L., Wang, B. and Wang, Y. (2004) Impacts of Re-greening the Desertified Lands in Northwestern China: Implications from a Regional Climate Model Experiment. Journal of the Meteorological Society of Japan, v. 82(6), pp. 1679-1693.

13. Liu, Y., Giorgi, F. and Washinton, W. M. (1994) Simulation of Summer Monsoon Climate over East Asia with an NCAR Regional Climate Model. Monthly Weather Review, v. 122, pp. 2331-2348.

14. Huang, W. R., Chan, J. C. L. and Yeung, A. Y. M. (2013) Regional climate simulations of summer diurnal rainfall variations over East Asia and Southeast China. Climate Dynamics, v. 40(7-8), pp. 1625-1642.

15. Dash, S. K., Shekhar, M. S. and Singh, G. P. (2006) Simulation of Indian summer monsoon circulation and rainfall using RegCM3. Theoretical and Applied Climatology, v. 86, pp. 161-172.

16. Nayak, S., Mandal, M. and Maity, S. (2017) Customization of regional climate model (RegCM4) over Indian region. Theoretical and Applied Climatology, v. 127(1-2), pp. 153168.

17. Maity, S., Mandal, M., Nayak, S. and Bhatla, R. (2017b) Performance of cumulus parameterization schemes in the simulation of Indian Summer Monsoon using RegCM4. Atmósfera, v. 30(4), pp. 287-309.

18. Bell, G. D., Halpert, M. S., Ropelewski, C. F., Kousky, V. E., Douglas, A. V., Schnell, R. C. and Gelman, M. E. (1999) Climate assessment for 1998. Bulletin of the
American Meteorological Society, $v$. 80(5s), pp. S1-S48.

19. Giorgi, F., Marinucci, M. R. and Bates, G. T. (1993a) Development of a second generation regional climate model (RegCM2). Part I: Boundary layer and radiative transfer processes. Monthly Weather Review, v. 121, pp. 2794-2813.

20. Giorgi, F., Marinucci, M. R., Bates, G. T. and De Canio, G. (1993b) Development of a second generation regional climate model (RegCM2). Part II: Convective processes and assimilation of lateral boundary conditions. Monthly Weather Review, v. 121, pp. 2814-2832.

21. Pal, J. S., Giorgi, F., Bi, X., Elguindi, N., Solmon, F., Gao, X., Rauscherm, S. A., Francisco, R., Zakey, A., Winter, J., Ashfaq, M., Syed, F. S., Bell, J. L., Diffenbaugh, N. S., Karmacharya, J., Konare, A., Martinez, D., Da Rocha, R. P., Sloan, L. C. and Steiner, A. L. (2007) Reglonal climate modeling for the developing world: the ICTP RegCM3 and RegCNET. Bulletin of the American Meteorological Society, v. 88(9), pp. 1395-1409.

22. Holtslag, A. A. M., De Bruijn, E. I. F. and Pan, H. L. (1990) A high resolution air mass transformation model for short-range weather forecasting. Monthly Weather Review, v. 118, pp. 1561-1575.

23. Nayak, S. (2018) Do extreme precipitation intensities linked to temperature over India follow the Clausius-Clapeyron relationship? Current Science, v. 115(3), pp. 391392.

24. Nayak, S. and Mandal, M. (2012) Impact of Land Use and Land Cover Change on Temperature Trends over Western India. Current Science, v. 102(8), pp. 1166-1173. 
25. Nayak, S., Maity, S., Singh, K. S., Nayak, H. P., and Dutta, S. (2021). Influence of the Changes in LandUse and Land Cover on Temperature over Northern and North-Eastern India. Land, 10, 52.

26. Nayak, S. and Mandal, M. (2019a) Impact of land use and land cover changes on temperature trends over India. Land Use Policy, v. 89, pp. 104238.

27. Nayak, S. and Mandal, M. (2019b) Examining the impact of regional land use and land cover changes on temperature: the case of Eastern
India. Spatial Information Research, v. 27(5), pp. 601-611.

28. Sruthi Krishnan, V. (2021). Impact of land use and land cover change on the environmental quality of a region: A case of Ernakulam district in Kerala, India. Regional Statistics, 2, 102-135

29. Nayak, S. and Behera, M. D. (2008) Land use/land cover classification and mapping of Pilibhit District Uttar Pradesh India. The Indian Geographical Journal, v. 83(1), pp. 15-24. 